\title{
Design and Build Reminder for Arduino Based Drug Schedule Consumption System
}

\section{Rancang Bangun Sistem Pengingat Jadwal Konsumsi Obat Berbasis Arduino}

\author{
Moch Faizal Deva Prayogo ${ }^{\mathbf{1}}$, Wahyu Sapto Aji ${ }^{1,2}$ \\ ${ }^{1}$ Universitas Ahmad Dahlan, Indonesia \\ ${ }^{2}$ Universiti Malaysia Pahang, Malaysia
}

\section{INFORMASI ARTIKEL}

\section{Riwayat Artikel:}

Dikirimkan 31 Agustus 2019, Dikirimkan 26 April 2020, Dikirimkan 10 Juni 2020.

\section{Kata Kunci:}

Arduino,

Obat,

RTC (Real Time Clock),

buzzer

Alarm.

\section{Penulis Korespondensi:}

Wahyu Sapto Aji,

Teknik Elektro, Universitas

Ahmad Dahlan,

Kampus IV, Jl. Ring Road

Selatan, Tamanan,

Banguntapan, Bantul

Yogyakarta 55166

Surel: wahyusaji@gmail.com

\begin{abstract}
ABSTRAK
The medication reminder system is designed to set the patient's daily drug consumption schedule. This system uses RTC DS1302 as a time saver and as an alarm, while the output is in the form of a buzzer and LED. Schedule of drug consumption can be arranged morning, afternoon, and evening according to patient needs. On the device there is a DVD motor drive that is used to extract the drug automatically. There is also a temperature sensor in the form of DHT11 to monitor the temperature of the device, so that the quality of the drug is maintained. The system was tested using 3 drug slots in it. The device is set using a keypad to make it easier for patients to manage medication consumption schedules. After being tested, the results of the alarm output sound in the form of a buzzer. and the output of a medicine container that uses a DVD motor automatically. After the device is tested, an alarm in accordance with what is set schedule indicates the tool is running in accordance with the destination.
\end{abstract}

Pada sistem pengingat obat dirancang untuk mengatur jadwal konsumsi obat keseharian pasien. Sistem ini menggunakan RTC DS1302 sebagai penyimpan waktu dan sebagai alarm, sementara output berupa buzzer dan LED. Jadwal konsumsi obat dapat diatur pagi, siang, dan malam sesuai dengan kebutuhan pasien. Pada alat terdapat sebuah penggerak motor $D V D$ yang digunakan untuk mengeluarkan obat secara otomatis. Terdapat juga sensor suhu berupa DHT11 untuk memonitor suhu pada alat, sehingga kualitas obat tetap terjaga. Sistem diuji menggunakan 3 slot obat di dalamnya. Alat diatur menggunakan keypad untuk memudahkan pasien dalam mengatur jadwal konsumsi obat. Setelah diuji, hasilnya alarm mengeluarkan output berupa suara pada buzzer. serta keluaran wadah obat yang menggunakan motor DVD secara otomatis. Setelah alat diuji, alarm sesuai dengan apa yang sudah diatur jadwalnya menandakan alat berjalan sesuai dengan tujuan.

This work is licensed under a Creative Commons Attribution-Share Alike 4.0

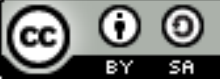

\section{Sitasi Dokumen ini:}

M. F. D. Prayogo and W. S. Aji, "Design and Build Reminder for Arduino Based Drug Schedule Consumption System," Buletin Ilmiah Sarjana Teknik Elektro, vol. 2, no. 2, pp. 75-82, 2020. DOI: 10.12928/biste.v2i2.1031 


\section{PENDAHULUAN}

Semakin pesat perkembangan teknologi modern, kegiatan manusia dapat mudahkan dengan bantuan teknologi modern. Masyarakat Indonesia menginginkan sebuah teknologi yang mampu membantu kegiatan mereka sehari-hari dengan harga yang relatif terjangkau [1][2].

Penggunaan obat dapat dikatakan hal sangat fatal dalam masalah pengobatan penyakit. Oleh karena itu obat harus mesti diberikan dengan cara yang tepat, jika tidak maka obat dapat memberikan efek yang tidak diharapkan dan bahkan dapat memberikan efek keracunan jika dosis yang diberikan tidak tepat [3]. Pasienpasien dengan penyakit komplikasi dan diharuskan mengonsumsi obat dalam jumlah yang banyak cenderung memiliki tingkat kepatuhan yang rendah [4][5]. Hal tersebut dikarenakan kecenderungan pasien yang lupa jadwal minum obatnya serta obat manakah yang harus dikonsumsi pada jam tersebut [6]. Strategi yang berbasis teknologi dapat meningkatkan perilaku pasien dalam terapi pengobatan yaitu dengan memberikan pelayanan pengobatan secara terkontrol pada pasien di rumah yang menggunakan teknologi dibidang kesehatan [2][7].

Perlu dilakukan upaya penelitian agar dapat mengetahui perubahan dari perilaku kepatuhan konsumsi obat sebelum dan sesudah pemberian layanan sistem pengingat pada pasien pengguna obat [8][9]. Oleh karena itu, pada penelitian akan membuat sebuah alat yang akan menangani pasien dalam mengingat jadwal minum obat serta obat manakah yang harus dikonsumsi pada saat itu. Sistem kerja alat ini menggunakan arduino sebagai mikrokontrolernya dengan dibantu RTC DS1302 sebagai pewaktu. Sehingga pasien hanya akan meletakkan obat pada alat kemudian mengatur aturan pakainya kemudian alat akan berbunyi jika sudah waktunya minum obat dan akan terus berbunyi sampai tombol pada alat ditekan [10].

RTC(Real Time Clock merupakan) adalah perangkat yang digunakan untuk mendapatkan waktu yang secara tepat atau masa kini [11]. Dilengkapi dengan pembangkit waktu serta baterai lithium yang digunakan untuk backup catu daya, sehingga data waktu yang sudah dimasukkan pada $R T C$ tidak akan hilang [12]. RTC mempunyai beberapa jenis, salah satu contoh pada Modul RTC DS1302 yang digunakan peneliti sebagai penyimpan waku secara realtime, serta menyimpan alarm yang sudah di-setting pada sistem pengingat obat tersebut. RTC (Real Time Clock) dapat menyimpan waktu berupa jam, menit, hari bulan, dan tahun [13]. RTC tersebut telah diatur untuk mengatur jadwal konsumsi obat.

Penelitian ini juga menggunakan $D H T 11$ yaitu merupakan modul sensor yang berfungsi mendeteksi suhu dan kelembaban, output berupa tegangan analog yang disambungkan ke mikrokontroler Arduino mega [14]. Sensor ini juga berfungsi menjaga suhu pada sistem pengingat obat, oleh karena itu kualitas obat akan terus terjaga [7]. Dengan adanya prototipe ini diharapkan dapat membantu pasien dalam mengonsumsi obat tepat waktu, sehingga persentase kepatuhan minum obat dapat meningkat.

\section{METODE PENELITIAN}

Penelitian ini mengusulkan tentang sistem penjadwalan obat jangka panjang. Penelitian dilakukan dengan perancangan hardware, kemudian dilanjutkan dengan pengujian sistem pada beberapa komponen untuk mengetahui apakah alat tersebut dapat dijalankan dengan baik atau tidak. Diagram blok perancangan pada hardware yang ditunjukkan pada Gambar 1.

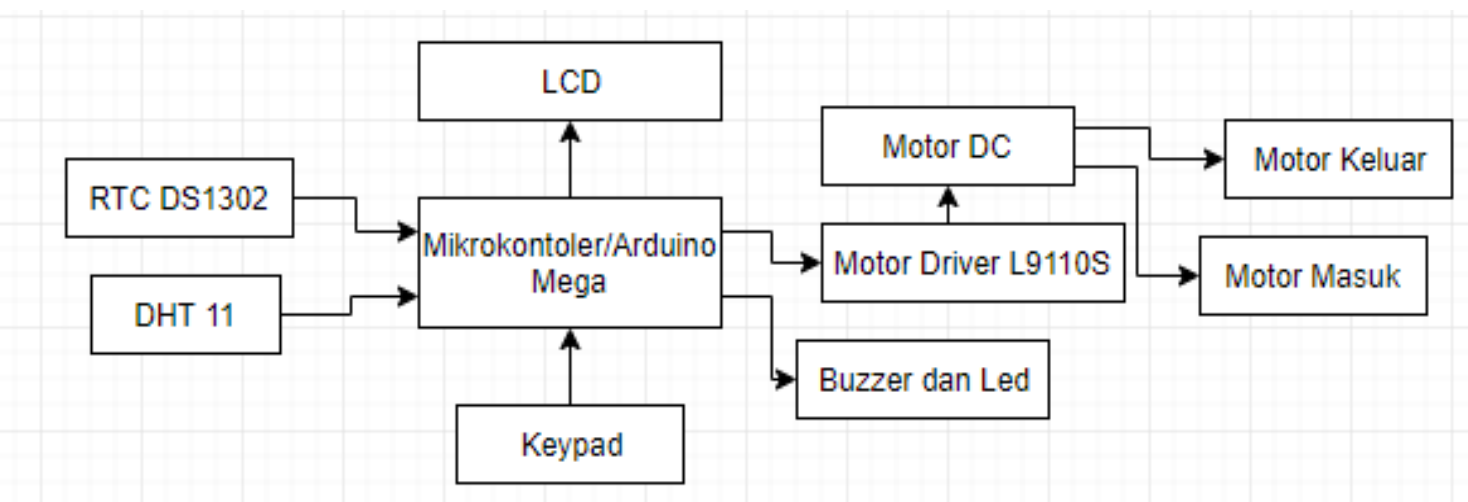

Gambar 1. Diagram Blok perancangan hardware

Gambar 1 merupakan diagram blok perancangan perangkat keras (hardware) dengan arduino mega sebagai pusat mikrokontroler. Button dan keypad berfungsi untuk mengatur waktu jadwal obat, LCD untuk menampilkan data, RTC berfungsi untuk memberikan data waktu, motor DVD berfungsi untuk menggerakkan kotak obat, Buzzer dan LED berfungsi sebagai indikator. Terdapat juga sensor DHT 11 yaitu sensor suhu yang secara otomatis akan menghasilkan output berupa suhu yang ditampilkan pada LCD. Dari perancangan hardware tersebut didapatkan hasil desain pada Gambar 2. 


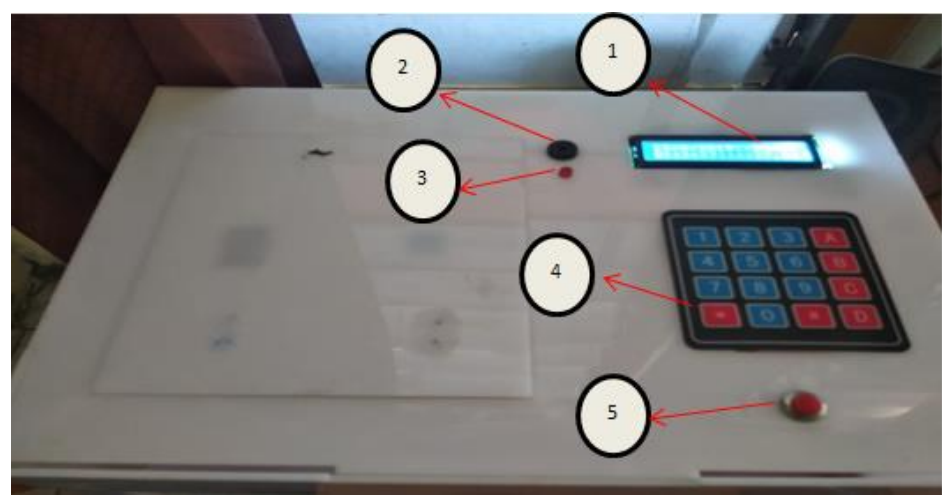

Gambar 2. Perancangan hardware

Keterangan pada Gambar 2 adalah sebagai berikut

1. LCD sebagai tampilan utama atau sebagai human interface.

2. Keypad sebagai tombol untuk mengatur alat.

3. Buzzer sebagai penanda alarm.

4. LED sebagai penanda, prinsip kerjanya sama seperti buzzer

5. Button sebagai tombol untuk mengeluarkan wadah obat.

Dalam sistem pengingat ini memiliki diagram alir yang ditunjukkan pada Gambar 3.

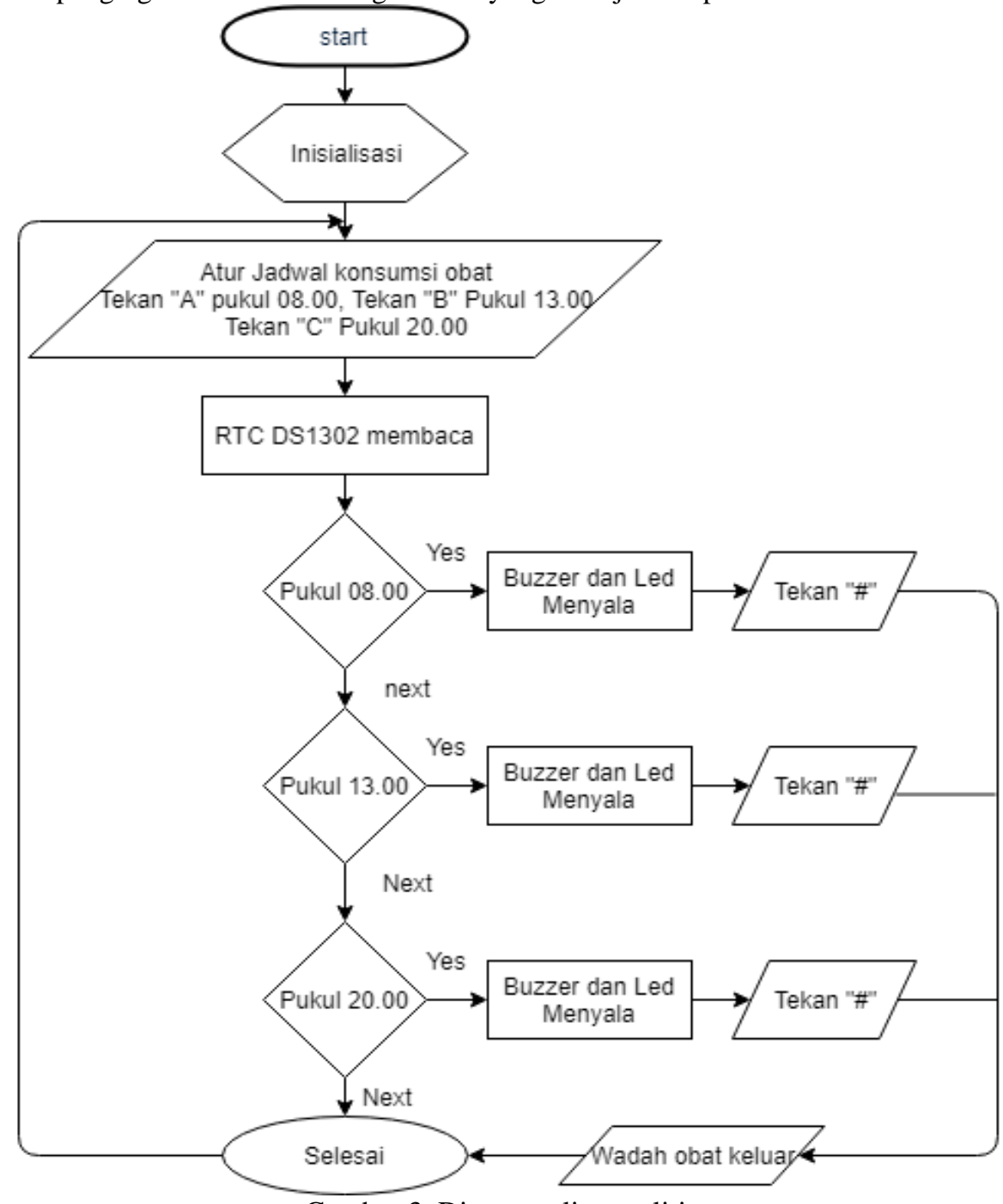

Gambar 3. Diagram alir penelitian 
Diagram alir pada sistem pengingat ditunjukkan pada gambar 3, proses pertama yaitu mengatur jadwal konsumsi pada alat yang terbagi 3 waktu. Waktu terdiri dari pukul 08.00, 13.00 dan 20.00, setelah diatur, RTC DS1302 menyimpan waktu alarm tersebut yang nantinya jika sudah pada waktu yang ditentukan maka buzzer dan LED akan menyala secara bersamaan[10]. Setelah alarm menyala pada pukul 08.00, Alarm akan terus berbunyi sampai tombol keypad pada alat ditekan. Yang dilakukan selanjutnya mematikan alarm dengan menekan "\#”. Setelah alat ditekan maka obat akan keluar dari tempatnya selama 8 detik secara otomatis dengan menggunakan motor DC sebagai penggeraknya dan selanjutnya akan menutup kembali secara otomatis. Untuk waktu yang ke dua dan ke tiga sama seperti waktu yang pertama. Terdapat juga sensor DHT11 yang berfungsi memberitahu jika suhu lebih dari $30^{\circ}$ maka buzzer akan menyala. Diagram alir dari Sensor suhu yang berfungsi memonitor suhu pada alat ditunjukkan pada Gambar 4.

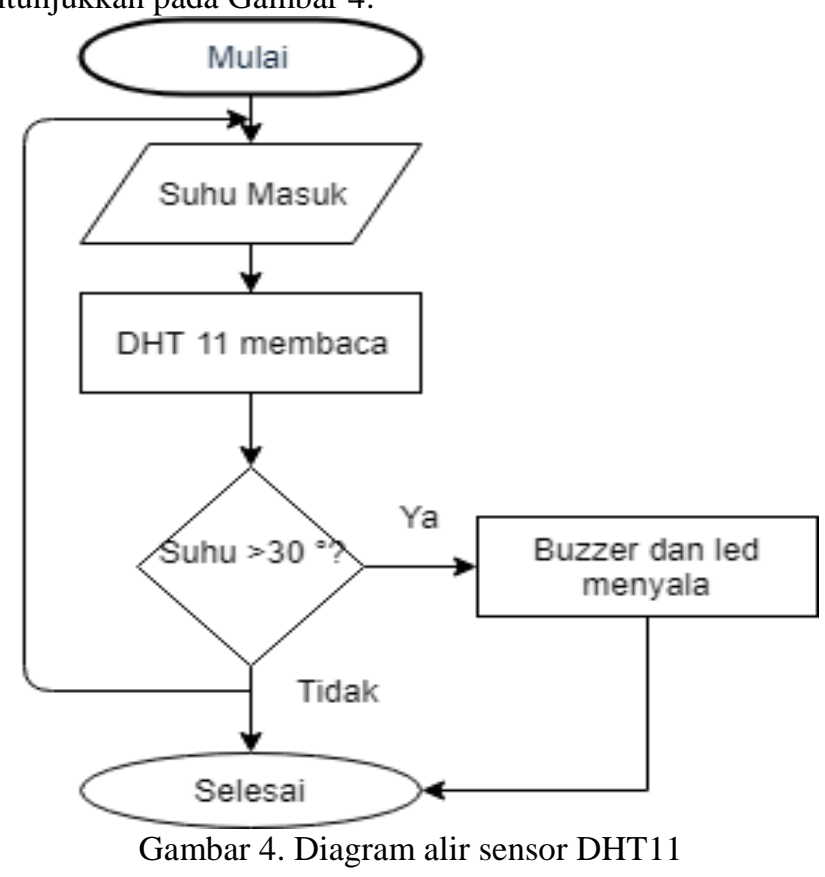

Diagram alir sensor DHT11 yang ditunjukkan pada Gambar 3.6 kerja sistemnya adalah suhu dideteksi oleh $D H T 11$ yang nantinya akan membaca jika suhu lebih dari $30^{\circ} \mathrm{C}$ maka buzzer dan led akan menyala secara bersamaan menandakan alat harus dipindah ke tempat yang lebih sejuk untuk menjaga kondisi obat. Buzzer akan mati jika suhu kembali turun atau pada posisi kurang dari $30^{\circ} \mathrm{C}$.

\section{HASIL DAN PEMBAHASAN}

Langkah berikutnya adalah melakukan hasil dari pengujian kinerja pada alat yang telah dirancang sedemikian rupa sehingga membentuk sistem. Pengujian bertujuan memaparkan hasil data dari sistem. Proses pengujian dilakukan dengan bertahap agar dapat mengetahui sistem dapat bekerja atau tidak.

\subsection{Pengujian RTC DS1302}

Pengujian timer pada RTC DS1302 dilakukan dengan memberikan nilai masukan awal yaitu memberikan waktu terbaru pada saat ini, RTC diatur supaya memunculkan waktu terbaru yang nantinya digunakan untuk menyimpan waktu, sehingga waktu yang ditampilkan sesuai dengan yang kita mau pada waktu tertentu. Pengujian RTC DS1302 ini menggunakan Arduino mega sebagai mikrokontrolernya yang mana pin CLK terletak pada kaki pin no 2, DAT terletak pada pin 3, serta RST pada pin 4. Setelah dirangkai maka diprogram melalui software arduino lalu ditampilkan pada $l c d$ berikut adalah tampilan yang menunjukkan hasil dari pengujian instruksi RTC ini berjalan ditunjukkan pada Gambar 5.

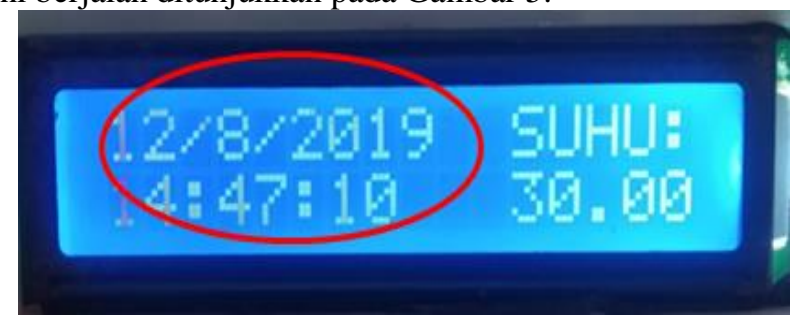

Gambar 5. Pengujian hasil tampilan RTC DS1302 
Pada Gambar 5 terlihat bahwa pengujian RTCDS1302 berhasil diuji. Tampilan pada LCD tersebut merupakan waktu masa kini (real time). Walaupun daya dimatikan dari sumbernya waktu real time akan tetap tersimpan. Kecuali jika baterai dari RTC DS1302 dilepas maka, harus mengatur ulang waktu real time. Setelah diuji pada tampilan langkah selanjutnya menguji dengan buzzer dan LED, tabel hasil pengujian ditunjukkan pada Tabel 1 .

Tabel 1. Pengujian RTC dengan buzzer dan LED

\begin{tabular}{|c|c|c|c|}
\hline $\begin{array}{c}\text { Hari } \\
\text { ke- }\end{array}$ & Waktu yang diatur & Buzzer dan Led & keterangan \\
\hline \multirow{3}{*}{1} & Pukul 08.00 & 1 & Menyala \\
\cline { 2 - 4 } & Pukul 13.00 & 1 & Menyala \\
\cline { 2 - 4 } & Pukul 20.00 & 1 & Menyala \\
\hline \multirow{3}{*}{2} & Pukul 07.30 & 1 & Menyala \\
\cline { 2 - 4 } & Pukul 12.30 & 1 & Menyala \\
\cline { 2 - 4 } & Pukul 19.00 & 1 & \\
\hline
\end{tabular}

Dari tabel 1 merupakan hasil dari pengujian RTC dengan buzzer. Hasilnya berjalan dengan baik dan sesuai dengan yang diharapkan. Pengujian dilakukan selama 2 hari dengan waktu yang berbeda.

\subsection{Pengujian Sensor DHT11}

Pengujian sensor suhu dilakukan untuk mengukur suhu dalam ruang penyimpanan obat dikarenakan obat harus selalu terjaga suhunya. Sensor akan membaca suhu pada ruang penyimpanan obat yang nantinya akan ditampilkan pada LCD untuk memantau suhu. Pengujian sensor ini bertujuan untuk melihat apakah sensor dapat berjalan dan tampil pada LCD dan bertujuan juga untuk menghindari kerusakan pada obat. Hasil tampilan dari pengujian sensor DHT 11 ditunjukkan pada Gambar 6.

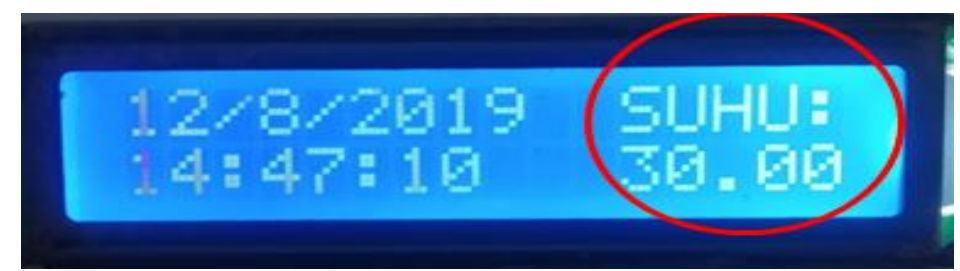

Gambar 6. Hasil tampilan pengujian DHT11

Dari Gambar 6 merupakan hasil dari pengujian pada gambar didapatkan suhu normal ( $30^{\circ} \mathrm{C}$ ) atau suhu awal yang muncul pada LCD pertama kali. Terdapat beberapa tempat untuk pengujian DHT 11, di antaranya pada tempat yang dingin, hingga tempat yang hangat. Untuk pengukuran hasil data dilakukan dengan cara memindahkan alat ke berbagai tempat yang kondisi suhunya berbeda dengan suhu maksimal dan suhu minimal pada kondisi yang berbeda. Hasil pengukuran suhu DHT 11 ditunjukkan pada Tabel 2.

Tabel 2. Hasil pengukuran Sensor DHT 11

\begin{tabular}{|c|c|c|c|c|c|c|}
\hline \multirow{2}{*}{ Fase pengukuran } & \multirow{2}{*}{$\begin{array}{c}\text { Pengukuran } \\
\text { menggunakan } \\
\text { termometer Digital }\end{array}$} & \multicolumn{2}{|c|}{$\begin{array}{c}\text { Pengujian menggunakan } \\
\text { sensor DHT11 }\end{array}$} & \multirow{2}{*}{$\begin{array}{l}\text { Rata-rata } \\
\text { pengujian }\end{array}$} & \multirow{2}{*}{ Selisih } & \multirow{2}{*}{$\begin{array}{l}\text { error } \\
(\%)\end{array}$} \\
\hline & & $\begin{array}{l}\text { Pengujian } \\
\text { Hari ke-1 }\end{array}$ & $\begin{array}{l}\text { Pengujian } \\
\text { Hari ke-2 }\end{array}$ & & & \\
\hline Suhu Awal muncul & $29,4^{\circ} \mathrm{C}$ & $30^{\circ} \mathrm{C}$ & $29^{\circ} \mathrm{C}$ & $29,5^{\circ} \mathrm{C}$ & 0,1 & 0,34 \\
\hline Ruangan berAC & $19,8^{\circ} \mathrm{C}$ & $19^{\circ} \mathrm{C}$ & $21^{\circ} \mathrm{C}$ & $20^{\circ} \mathrm{C}$ & 0,2 & 1,01 \\
\hline Tempat terbuka & $30,7^{\circ} \mathrm{C}$ & $31^{\circ}$ & $31^{\circ} \mathrm{C}$ & $31^{\circ} \mathrm{C}$ & 0,3 & 0,98 \\
\hline Tempat lembab & $26,5^{\circ} \mathrm{C}$ & $28^{\circ} \mathrm{C}$ & $27^{\circ} \mathrm{C}$ & $27,5^{\circ} \mathrm{C}$ & 1 & 3,77 \\
\hline $\begin{array}{l}\text { Terkena sinar } \\
\text { matahari }\end{array}$ & $33,1^{\circ} \mathrm{C}$ & $34^{\circ} \mathrm{C}$ & $33^{\circ} \mathrm{C}$ & $33,5^{\circ} \mathrm{C}$ & 0,4 & 1,2 \\
\hline $\begin{array}{l}\text { Langsung di bawah } \\
\text { paparan sinar matahari }\end{array}$ & $34,4^{\circ} \mathrm{C}$ & $35^{\circ} \mathrm{C}$ & $34^{\circ} \mathrm{C}$ & $34,5^{\circ} \mathrm{C}$ & 0,1 & 0,2 \\
\hline
\end{tabular}


Dari hasil pengukuran sensor pada Tabel 2, didapatkan hasil suhu maksimal dengan $35^{\circ}$, suhu maksimal didapat dengan pengujian manual yaitu sensor diberi suhu panas yang bertahap dari fase peletakan di lemari pendingin hingga sampai dengan peletakan di bawah paparan sinar matahari langsung. Dan terdapat nilai error pada sensor, nilai error didapatkan dengan menghitung selisih antara suhu rata-rata dengan suhu pembanding yaitu menggunakan termometer, lalu dibagi dengan suhu pembanding dan dikali $100 \%$.

\subsection{Pengujian Motor DVD}

Pengujian ini dilakukan untuk mengetahui gerak atau tidaknya dari pintu otomatis, yang dibuat memudahkan dalam mengambil obat. Prinsip kerjanya sama seperti tempat keluar masuknya CD ROM pada personal komputer memudahkan dalam mengambil kaset CD. Sama halnya dengan prinsip kerja motor DC ini yaitu menggerakkan wadah obat jika tekan tombol "\#” maka wadah akan keluar dengan sendirinya. Berikut adalah tampilan dari wadah obat yang ditunjukkan pada Gambar 7.

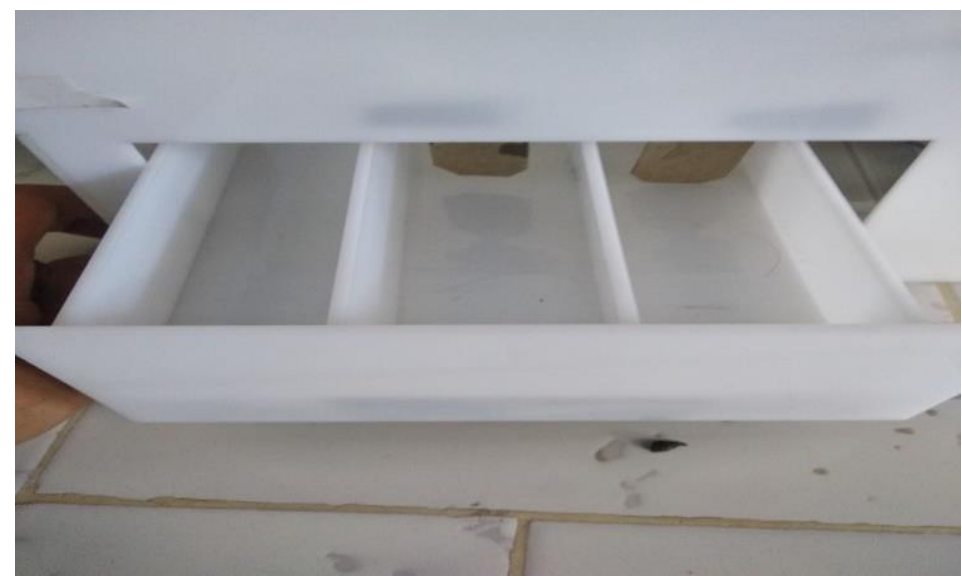

Gambar 7. Wadah obat

Dari Gambar 7 terlihat bahwa tempat obat yang berisikan 3 tempat yang berbeda keluar dengan otomatis. Ketika pasien sudah menekan tombol "\#” pada keypad, maka pasien mendapat beberapa waktu jeda selama 8 detik untuk mengambil obat yang nantinya akan wadah obat tersebut akan menutup kembali secara otomatis. Selanjutnya adalah mengukur tegangan dari motor DVD yang menggunakan driver motor L9110S. Pengukuran menggunakan multimeter digital karena lebih mudah dalam membaca angkanya. Berikut adalah hasil pengukuran tegangan pada motor DVD yang ditunjukkan dengan Tabel 3.

Tabel 3. Pengukuran tegangan motor DVD

\begin{tabular}{|c|c|c|c|}
\hline \multirow{2}{*}{$\begin{array}{c}\text { Hari } \\
\text { ke- }\end{array}$} & \multirow{2}{*}{ Waktu Pengujian } & \multicolumn{2}{|c|}{ Tegangan yang dihasilkan (volt) } \\
\hline & & Wadah obat Keluar & Wadah Obat Masuk \\
\hline \multirow{3}{*}{1} & Pukul 08.00 & 3,54 & 3,49 \\
\hline & Pukul 13.00 & 3,61 & 3,37 \\
\hline & Pukul 20.00 & 3,51 & 3,3 \\
\hline \multirow{3}{*}{2} & Pukul 08.00 & 3,63 & 3,54 \\
\hline & Pukul 13.00 & 3,5 & 3,32 \\
\hline & Pukul 20.00 & 3,94 & 3,61 \\
\hline \multicolumn{2}{|r|}{$\Sigma$} & 21,73 & 20,63 \\
\hline \multicolumn{2}{|r|}{ Rata-rata } & 3,621 & 3,438 \\
\hline
\end{tabular}

Dari Tabel 2 didapatkan hasil data berupa pengukuran tegangan pada driver motor L9110S . Hasilnya pada saat wadah obat keluar mendapatkan nilai rata-rata tegangan 3,621 Volt dan sedangkan pada wadah obat menutup atau masuk kembali didapatkan nilai rata-rata tegangan sebesar 3,438 Volt. Pengukuran dilakukan dengan dua kondisi, kondisi pertama yaitu pada saat wadah obat membuka dan kondisi kedua pada saat wadah obat menutup kembali. Selanjutnya dilakukan 6 kali pengujian berdasarkan waktu yang telah ditentukan. 


\subsection{Pengujian Sistem Keseluruhan}

Untuk memastikan alat ini bekerja dengan baik, maka dilakukan proses pengujian terhadap Alat. Pengujian dilakukan di berbagai tempat agar sensor dapat membaca kondisi ruangan serta dapat mendapatkan hasil data yang sesuai diharapkan peneliti. Pada pengujian ini dilakukan 2 hari sehingga dapat menyajikan data proses pengujian yang ditunjukkan pada Tabel 4.

Tabel 4. Hasil Pengujian keseluruhan sistem

\begin{tabular}{|c|c|c|c|c|c|c|}
\hline $\begin{array}{l}\text { Hari } \\
\text { ke }\end{array}$ & $\begin{array}{l}\text { Waktu } \\
\text { (Jam) }\end{array}$ & Tempat & $\begin{array}{l}\text { Buzzer } \\
\text { dan led }\end{array}$ & $\begin{array}{l}\text { Pergerakan motor } \\
\text { (wadah Obat) }\end{array}$ & $\begin{array}{l}\text { Sensor suhu } \\
\text { mendeteksi }\end{array}$ & $\begin{array}{l}\text { Buzzer mendeteksi } \\
\text { suhu }>30^{\circ}\end{array}$ \\
\hline \multirow{3}{*}{1} & 08.00 & $\begin{array}{l}\text { Ruang } \\
\text { Ber-AC }\end{array}$ & 1 & 1 & $19^{\circ} \mathrm{C}$ & 0 \\
\hline & 13.00 & $\begin{array}{l}\text { Terkena } \\
\text { sinar } \\
\text { matahari }\end{array}$ & 1 & 1 & $33^{\circ} \mathrm{C}$ & 1 \\
\hline & 20.00 & $\begin{array}{l}\text { Kamar } \\
\text { terbuka }\end{array}$ & 1 & 1 & $30^{\circ}$ & 0 \\
\hline \multirow{3}{*}{2} & 08.00 & $\begin{array}{c}\text { Lemari } \\
\text { pendingi } \\
\mathrm{n}\end{array}$ & 1 & 1 & $17^{\circ} \mathrm{C}$ & 0 \\
\hline & 13.00 & $\begin{array}{l}\text { Di bawah } \\
\text { langsung } \\
\text { sinar } \\
\text { matahari }\end{array}$ & 1 & 1 & $35^{\circ} \mathrm{C}$ & 1 \\
\hline & 20.00 & $\begin{array}{l}\text { Ruangan } \\
\text { lembab }\end{array}$ & 1 & 1 & $28^{\circ}$ & 0 \\
\hline
\end{tabular}

Dari hasil pengujian keseluruhan sistem alat dapat terlihat. Bahwa alat berhasil diujikan, hasil keberhasilan didapatkan dari pengujian alarm pada RTC DS1302, Motor DC, dan sensor DHT 11. Alarm yang diatur oleh pasien nantinya akan tersimpan pada $R T C$ yang dikendalikan Arduino lalu diteruskan pada tampilan LCD, yang selanjutnya mengirimkan pada output buzzer dan led. Sensor suhu membaca suhu pada suatu kondisi ruangan dengan rentan suhu dari $17^{\circ} \mathrm{C}-35^{\circ} \mathrm{C}$. Ketika $D H T 11$ membaca suhu lebih dari $30^{\circ} \mathrm{C}$, maka mikrokontroler menerima pesan dari DHT11 yang nantinya akan menghasilkan output pada buzzer dan led, diharuskan untuk memindahkan alat ke yang lebih stabil suhunya.

\section{KESIMPULAN}

Setelah melakukan perencanaan dan pembuatan sistim kemudian dilakukan pengujian dan analisanya, maka dapat diambil beberapa kesimpulan tentang sistem kerja dari rancang bangun sistem pengingat jadwal konsumsi obat yaitu, Alat pengingat dapat dirancang dengan menggunakan Arduino sebagai mikrokontroler dan sesuai setting waktu alarm yang diinginkan pengguna. Alarm diatur dalam 3 waktu yang berbeda dalam satu hari.

\section{UCAPAN TERIMA KASIH}

Saya ucapkan banyak terima kasih kepada editor dan reviewer atas segala saran dan masukan, dan terima kasih juga telah membantu dalam proses penerbitan naskah. Ucapan terima kasih juga saya tunjukkan kepada pihak-pihak yang telah mendukung penelitian dan memberikan bantuan moral dan material.

\section{REFERENSI}

[1] G. N. Sevani, “Aplikasi Reminder Pengobatan Pasien Berbasis SMS Gateway,” INKOM: Jurnal Informatika, Sistem Kendali dan Komputer, vol. 7, no. 1, pp. 11-20, 2013.

[2] I. K. Lubis, A. Harjoko, and F. S. T. Dewi, "Desain Sistem Pengingat Berbasis SMS untuk Meningkatkan Kepatuhan Pengobatan Pasien Diabetes Melitus," J. Inf. Syst. Public Heal., vol. 1, no. 1, pp. 3-9, 2016.

[3] P. Kesehatan and P. Dan, "Pengetahuan Dan Stigma Masyarakat Terhadap Tbc Setelah Diberikan Pendidikan Kesehatan Pencegahan Dan Penularan," Jurnal Keperawatan Soedirman, vol. 10, no. 2, pp. 76-82, 2015.

[4] J. S. Farmasi, P. Pameswari, A. Halim, and L. Yustika, "Tingkat Kepatuhan Penggunaan Obat pada Pasien Tuberkulosis di Rumah Sakit Mayjen H . A . Thalib Kabupaten Kerinci," Jurnal Sains Farmasi \& Klinis, vol. 2, no. 2, pp. 116-121, 2016 
[5] A. S. Barouni, Z. B. Alnajh, N. B. Aboguttaia, and W. M. Alamri, "Evaluation of the BD MGIT TM TBc identification test for rapid identification of Mycobacterium tuberculosis Complex from positive BACTEC MGIT 960 cultures in a routine laboratory work," African Journal of Microbiology Research, vol. 6, no. 5, pp. 1065-1068, 2012.

[6] K. Minum, O. Penderita, and K. Di, "Faktor-Faktor Yang Berhubungan Dengan Tingkat Kepatuhan Minum Obat Penderita Kusta Di Kabupaten Brebes," Unnes Journal of Public Health, vol. 2, no. 3, pp. 58-66, 2015.

[7] A. K. Susanto, G. Citraningtyas, and W. A. Lolo, Penyimpanan dan Pendistribusian Obat di Gudang Instalasi Farmasi Rumah Sakit Advent Manado," PHARMACON, vol. 6, no. 4, 88-96, 2017.

[8] Y. Susanto, R. Alfian, I. Rusmana, P. Melati, and K. Kapuas, "Pengaruh Layanan Pesan Singkat Pengingat Terhadap Kepatuhan Konsumsi Obat Pasien Dm Tipe 2 Di Puskesmas Melati Kabupaten Kapuas," Jurnal Ilmiah Manuntung, vol. 3, no. 1, pp. 34-42, 2017.

[9] M. Gero, Sabina and Sayuna, "Pencegahan Penyakit TBC Paru Yang Utama Dimulai Dari Dalam Rumah Penderita," Jurnal Info Kesehatan, vol. 15, no.1, pp.120-128 2015.

[10] S. Irjayanto and A. N. N. Chamim, "Prototipe Kotak Pengingat Minum Obat," Semesta Teknika, vol. 18, no. 2, pp. 182-189, 2015.

[11] A. Nugraha, A. C. Kusuma, and B. Hasan, "Penyiram Tanaman Otomatis Berbasis Arduino," Prosiding Semnastek, vol. 1, no.1, 2019.

[12] A. Smart, C. Sebagai, D. Elektronik, C. W. Gunardi, and L. Wijayanti, "Aplikasi Smart Card Sebagai Dompet Elektronik Dan Penyimpan Kupon Pada Alat Permainan,” J. ELEKTRO, vol. 11, no. 1, pp. 56-67, 2018.

[13] S. M. Sutan, D. Kadarisman, S. Hosni, and F. Fadlillah, "Rancang Bangun Sistem Irigasi dan Pemberian Nutrisi Otomatis Berbasis Rtc (Real Time Clock) pada Sistem Hidroponik Nutrien Film Technique (NFT)," Jurnal Keteknikan Pertanian Tropis dan Biosistem, vol. 5, no. 2, pp. 117-128, 2017.

[14] F. Hafni, "Sistem Pengamatan Suhu dan Kelembapan pada Jamur Menggunakan Sensor DHT-11 Berbasis Atmega328p dengan Tampilan Menggunakan LCD,” 2018.

[15] S. R. M. Zeebaree and H. M. Yasin, "Arduino Based Remote Controlling for Home: Power Saving, Security and Protection," International Journal of Scientific \& Engineering Research, vol. 5, no. 8, pp. 266-272, 2014.

\section{BIOGRAFI PENULIS}

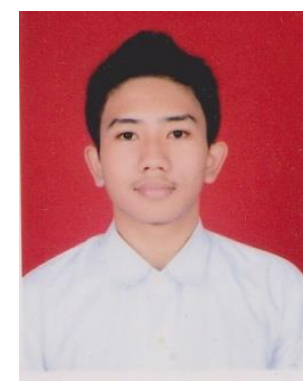

Moch Faizal Deva Prayogo

Penulis 1 adalah mahasiswa Program Studi teknik Elektro Universitas Ahmad Dahlan.

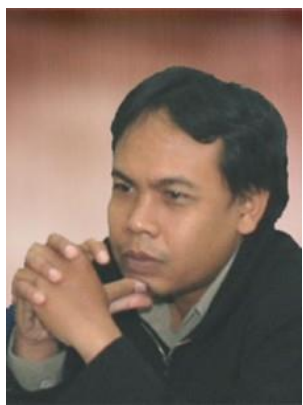

\section{Wahyu Sapto Aji}

Penulis 2 adalah dosen Program Studi Teknik Elektro Universitas Ahmad Dahlan. 